\title{
Oligoarticular Psoriatic Arthritis: Addressing Clinical Challenges in an Intriguing Phenotype
}

Antonio Marchesoni

\begin{abstract}
Details continue to emerge on psoriatic arthritis, expanding our understanding of its pathogenesis and clinical features. This has led to the evolution of management guidelines, which now recognize additional disease manifestations. In this rapidly changing area, it is timely to review the latest evidence and discuss whether management strategies are meeting patients' needs.
\end{abstract}

Funding: Celgene Corporation.

Keywords: Guidelines;

Management; Oligoarticular; Phenotype; Psoriatic arthritis; Treatment

\section{PSORIATIC ARTHRITIS:}

\section{A HETEROGENOUS DISEASE WITH DISTINCT PHENOTYPES AND DIVERSE MANIFESTATIONS}

Our deeper understanding of the immunological mechanisms of psoriatic arthritis (PsA) has, in recent years, driven the development of several new therapeutic options for this disease. Combined with improved treatment strategies,

Enhanced digital features To view enhanced digital features for this article go to https://doi.org/10.6084/ m9.figshare.6264890.

A. Marchesoni ( $\square)$

ASST Gaetano Pini-CTO, Milan, Italy

e-mail: antonio.marchesoni@asst-pini-cto.it advances in imaging techniques, and recognition of the heterogeneity of PsA, we are progressively improving the management of this disease [1].

Treatment and classification guidelines now identify up to six PsA disease domains: peripheral arthritis, enthesitis, dactylitis, spondylitis, and skin and nail psoriasis [2-4]. Patients can present with a unique combination and severity of these disease domains, leading to an individual burden of disease [5]. Additionally, patients with PsA are prone to comorbidities, such as obesity, metabolic syndrome, non-alcoholic fatty liver disease, and cardiovascular disease, which further contribute to disease heterogeneity and can complicate disease management [6].

This heterogeneity also means that diagnosing PsA can present a substantial clinical challenge [7]. The disease was initially defined as an inflammatory arthritis with coinciding psoriasis that is usually negative for rheumatoid factor [8] - a definition that has since been redefined to accommodate the possibility of additional features, including family history of psoriasis, dactylitis, enthesitis, and nail dystrophy [2]. Despite this redefinition, PsA presentation can be similar to other arthropathies and diagnosis, and therefore remains a challenge. Symmetrical polyarticular PsA can be misdiagnosed as rheumatoid arthritis (RA), both PsA and osteoarthritis can affect the distal interphalangeal (DIP) joints, and psoriatic polyenthesitis 
may be indistinguishable from fibromyalgia [9-11]. Differential diagnosis becomes particularly difficult in patients without other manifestations of PsA, such as skin, nail, and DIP joint involvement. The accurate diagnosis of PsA is essential considering its peculiarities of genetics and mechanistics $[10,12]$ that result in distinct disease progression and prognosis [13-15].

The classical distinction of PsA into five phenotypes-symmetrical polyarthritis, asymmetrical oligoarthritis and monoarthritis, arthritis mutilans, predominant DIP joint and predominant spondyloarthritis-is still valid, although the enthesitic subtype should be added [16]. Oligoarticular PsA, a less erosive form of disease, is more commonly reported in early disease and can progress to the more erosive polyarticular disease [16-19]. This disease progression, along with inconsistent definitions of oligoarticular and polyarticular PsA, may contribute to the variability in estimates of the prevalence of oligoarticular PsA, which range from 13 to $65 \%$ [16].

Given the unique presentation of disease in individual patients, early diagnosis and phenotypic classification of PsA could enable specific treatment strategies that target distinct needs associated with each phenotype. Effective application of an appropriately tailored disease management approach may halt progression to the polyarticular phenotype-a concept supported by data suggesting an early diagnosis can improve long-term outcomes [20].

\section{OLIGOARTICULAR PSA: A DISTINCT DISEASE PHENOTYPE}

\section{Clinical Challenges in Classification}

The well-established clinical definition of an oligoarticular PsA phenotype is the involvement of fewer than five active joints at a distinct timepoint [7]. However, the methodology used to measure joint activity can vary, resulting in non-uniform classification of patients.

The Group for Research and Assessment of Psoriasis and Psoriatic Arthritis and the Outcome Measures in Rheumatology (OMERACT) group recommends evaluating 66 joints using the swollen joint count (SJC) and 68 joints using the tender joint count (TJC) (66/68-joint count) for the assessment of peripheral arthritis $[21,22]$. In some clinical trials, and in general clinical practice, reduced joint counts (28- and 44 -joint counts) originally designed for use in RA may be implemented. However, an evaluation of both these methods in patients with oligoarticular PsA concluded that disease activity cannot be accurately assessed using a reduced joint count due to the potential for active joints to be missed [22]. Another system to evaluate the number of affected joints is to consider all joints ever involved (cumulative joint count). However, this system seems more appropriate for research studies than for clinical assessment [23]. Furthermore, the classification of PsA becomes more complicated when advanced imaging techniques are used, since detection of asymptomatic inflammation via imaging may result in reclassification of patients from oligoarticular to polyarticular PsA $[19,24]$.

Overall, the key in the clinic is consistency of assessment in order to allow phenotypic comparisons that guide clinical decision-making. The most convenient method to evaluate the pattern and activity of peripheral joint disease in clinical practice appears to be examination using the 66/68-joint count at a specific timepoint.

\section{Unmet Clinical Need in Oligoarticular PsA}

The Multinational Assessment of Psoriasis and Psoriatic Arthritis study revealed that patients are being undertreated, with 59\% receiving no therapy for their PsA. More than half of patients receiving conventional disease-modifying antirheumatic drugs [cDMARDs; with 69\% receiving methotrexate (MTX)] found their therapy burdensome, which was most commonly attributed to side effects and the need for laboratory monitoring [5]. Another study reported that two-thirds of patients with PsA experience residual disease, with almost half of these having moderate-to-high disease activity [25]. Treatments were not being adjusted in these 
patients, despite $74 \%$ receiving cDMARDs or their first biological tumor necrosis factor (TNF) inhibitor [25].

Increased joint involvement is associated with an elevated burden of disease, as measured by the eight-item Health Assessment Questionnaire Disability Index [5]. However, this measure also revealed that the presence of dactylitis and enthesitis can distinguish a more burdensome disease in patients with PsA [5]. Despite oligoarticular PsA being considered less severe than polyarticular disease, these patients still present with multiple domain involvement, notably dactylitis and enthesitis $[22,23]$. Interestingly, one study reported a higher prevalence of axial symptoms, dactylitis, and comorbidities in oligoarticular PsA compared to polyarticular PsA [26]. Potentially, therefore, oligoarticular PsA in the presence of additional disease domains and comorbid conditions may be identified as a phenotype associated with a specific unmet need.

\section{TREATING TO PHENOTYPE: PRACTICAL IMPLICATIONS IN THE CLINIC}

Therapeutic success can be difficult to assess in PsA due to the involvement of multiple disease domains of varied severity and a lack of consensus on validated outcome measures [27]. Due to the heterogenous needs of the individual patient, a low disease state is considered an appropriate goal when full remission is not achievable [28].

Minimal disease activity (MDA), which has been used as a treatment goal in rheumatic diseases such as RA, is defined for PsA based on the key disease domains identified by the OMERACT group $[2,29]$. The PsA MDA criteria are based on cut-off values within multiple disease domains: joint and skin involvement, patient pain, global activity, enthesitis, and health-related quality of life [29].

The TIght COntrol of inflammation in early PsA (TICOPA) trial established that a tight control (TC) treatment approach (whereby treatment doses or options are escalated at 4-weekly periods, based on a predetermined paradigm, if MDA was not achieved) significantly improves the achievement of MDA in patients with PsA, compared with a standard-ofcare approach. In TICOPA, most patients received MTX, with $82 \%$ of the TC group reaching a target dose of $25 \mathrm{mg}$ at 12 weeks. A higher frequency of adverse events was observed in the TC group, which was associated with the rapid escalation of MTX dose [30].

Two studies analyzing data from the TICOPA trial, either in patients who received MTX or the entire cohort (91\% receiving MTX), showed that improvements in individual disease activity measures, such as SJC and TJC, and composite measures, such as the PsA Disease Activity Score and American College of Rheumatology 20\% improvement criteria, were better at 12 weeks in patients with polyarticular PsA compared with oligoarticular PsA [31, 32]. However, the proportion of patients achieving MDA at 12 weeks was higher in the oligoarticular PsA group [31]. This may be explained by the fact that MDA consists of cut-off values, so a patient group with lower baseline disease activity is more likely to achieve MDA despite a smaller improvement in the number of inflamed joints. Additionally, an analysis of cost per quality-adjusted life-year in the TICOPA trial showed that value for money was worse when using a TC approach in the oligoarticular PsA subgroup compared with polyarticular PsA [33].

A further explanation for the small response observed in disease domains in the oligoarticular PsA subgroup is that MTX may not be as effective in treating oligoarticular PsA as polyarticular PsA [32], a conclusion that seems to be supported by data from the MTX in PsA (MIPA) trial. In the MIPA trial, MTX, albeit at a lower dose (15 mg/week) than TICOPA, demonstrated no significant effect in patients with PsA compared with placebo, and any effect of MTX was reduced in patients with oligoarticular PsA compared with polyarticular PsA [34].

Variations in the predictors of drug survival between oligoarticular and polyarticular PsA support the distinction of these two subgroups as unique phenotypes of PsA. An observational study assessing the performance of anti-TNF 
therapy in oligoarticular and polyarticular PsA observed comparable 2-year survival rates in the two PsA phenotypes. However, the study noted differences for patient sex, whereby females with oligoarticular PsA were more likely to discontinue the therapy than males, and for the type of drug, with patients with polyarticular PsA receiving etanercept more likely to continue therapy than those receiving adalimumab [35].

Recent treatment guidelines do not recommend the use of cDMARDs in some of the disease domains of PsA, such as enthesitis and axial symptoms [3, 4] or dactylitis [4], due to limited evidence of cDMARD effectiveness in these domains [3, 36]. Treatment regimens should utilize and tailor new therapies to the phenotype of disease, considering all PsA disease manifestations, the presence of comorbid conditions and the need for continued monitoring once treatment has been initiated [3, 7]. No discrete indications are provided for the treatment of oligoarticular or polyarticular PsA, given the lack of evidence on this topic. Overall, the issue of a therapy specifically targeting oligoarticular PsA has not been properly addressed, and studies in this field are needed.

Addressing the needs of distinct PsA phenotypes is achievable using the currently available therapeutic tools; however, disease management practices must evolve to combine our understanding of a patient's unique needs alongside the distinct properties of each therapy.

\section{ACKNOWLEDGMENTS}

Celgene Corporation references. UKI\&I180094(1) / GLII-APR180025a.

Funding. The author received an honorarium from Celgene Corporation for preparation of the manuscript. Article processing charges were funded by Celgene Corporation.

Medical Writing and/or Editorial Assistance. Medical writing services were provided by Dr. Nicholas Moss from MediTech Media and funded by Celgene Corporation. The commentary has been fully reviewed for accuracy by Celgene Corporation.

Authorship. All named authors meet the International Committee of Medical Journal Editors (ICMJE) criteria for authorship for this article, take responsibility for the integrity of the work as a whole, and have given their approval for this version to be published.

Disclosures. Dr. A. Marchesoni has received honoraria and speaker fees from AbbVie, BMS, Celgene, Janssen, MSD, Novartis, Pfizer, and UCB.

Compliance with Ethics Guidelines. This article is based on previously conducted studies and does not contain any studies with human participants or animals performed by any of the authors.

Open Access. This article is distributed under the terms of the Creative Commons Attribution-NonCommercial 4.0 International License (http://creativecommons.org/licenses/ by-nc/4.0/), which permits any noncommercial use, distribution, and reproduction in any medium, provided you give appropriate credit to the original author(s) and the source, provide a link to the Creative Commons license, and indicate if changes were made.

\section{REFERENCES}

1. Olivieri I, D'Angelo S. Psoriatic arthritis in 2015: advancement continues in imaging, tight control and new drugs. Nat Rev Rheumatol. 2016;12(2):76-8.

2. Taylor W, Gladman D, Helliwell P, Marchesoni A, Mease $\mathrm{P}$, Mielants $\mathrm{H}$, et al. Classification criteria for psoriatic arthritis: development of new criteria from a large international study. Arthritis Rheum. 2006;54(8):2665-73.

3. Coates LC, Kavanaugh A, Mease PJ, Soriano ER, Laura Acosta FM, Armstrong AW, et al. Group for research and assessment of psoriasis and psoriatic arthritis: treatment recommendations for psoriatic arthritis 2015. Arthritis Rheumatol. 2016;68(5):1060-71. 
4. Marchesoni A, Olivieri I, Salvarani C, Pipitone N, D'Angelo S, Mathieu A, et al. Recommendations for the use of biologics and other novel drugs in the treatment of psoriatic arthritis: 2017 update from the Italian Society of Rheumatology. Clin Exp Rheumatol. 2017;35(6):991-1010.

5. Kavanaugh A, Helliwell P, Ritchlin CT. Psoriatic arthritis and burden of disease: patient perspectives from the population-based multinational assessment of psoriasis and psoriatic arthritis (MAPP) survey. Rheumatol Ther. 2016;3(1):91-102.

6. Husted JA, Thavaneswaran A, Chandran V, Eder L, Rosen CF, Cook RJ, et al. Cardiovascular and other comorbidities in patients with psoriatic arthritis: a comparison with patients with psoriasis. Arthritis Care Res (Hoboken). 2011;63(12):1729-35.

7. Ritchlin CT, Colbert RA, Gladman DD. Psoriatic arthritis. N Engl J Med. 2017;376(10):957-70.

8. Moll JM, Wright V. Psoriatic arthritis. Semin Arthritis Rheum. 1973;3(1):55-78.

9. Mahmood F, Coates LC, Helliwell PS. Current concepts and unmet needs in psoriatic arthritis. Clin Rheumatol. 2018;37(2):297-305.

10. Veale DJ, Fearon U. What makes psoriatic and rheumatoid arthritis so different? RMD Open. 2015;1(1):e000025 (eCollection 2015).

11. Marchesoni A, De Marco G, Merashli M, McKenna $\mathrm{F}$, Tinazzi I, Marzo-Ortega $\mathrm{H}$, et al. The problem in differentiation between psoriatic-related polyenthesitis and fibromyalgia. Rheumatology (Oxford). 2018;57(1):32-40.

12. Gladman DD, Antoni C, Mease P, Clegg DO, Nash P. Psoriatic arthritis: epidemiology, clinical features, course, and outcome. Ann Rheum Dis. 2005;64(Suppl 2):ii14-7.

13. Kavanaugh A, van der Heijde D, McInnes IB, Mease P, Krueger GG, Gladman DD, et al. Golimumab in psoriatic arthritis: one-year clinical efficacy, radiographic, and safety results from a phase III, randomized, placebo-controlled trial. Arthritis Rheum. 2012;64(8):2504-17.

14. Kavanaugh A, Ritchlin C, Rahman P, Puig L, Gottlieb AB, Li S, et al. Ustekinumab, an anti-IL-12/23 p40 monoclonal antibody, inhibits radiographic progression in patients with active psoriatic arthritis: results of an integrated analysis of radiographic data from the phase 3, multicentre, randomised, double-blind, placebo-controlled PSUMMIT-1 and PSUMMIT-2 trials. Ann Rheum Dis. 2014;73(6):1000-6.
15. Strand V, Sharp JT. Radiographic data from recent randomized controlled trials in rheumatoid arthritis: what have we learned? Arthritis Rheum. 2003;48(1):21-34.

16. Dhir V, Aggarwal A. Psoriatic arthritis: a critical review. Clin Rev Allergy Immunol. 2013;44(2):141-8.

17. Queiro-Silva R, Torre-Alonso JC, Tinture-Eguren T, Lopez-Lagunas I. A polyarticular onset predicts erosive and deforming disease in psoriatic arthritis. Ann Rheum Dis. 2003;62(1):68-70.

18. Simon P, Pfoehler C, Bergner R, Schreiber M, Pfreundschuh M, Assmann G. Swollen joint count in psoriatic arthritis is associated with progressive radiological damage in hands and feet. Clin Exp Rheumatol. 2012;30(1):45-50.

19. Eder L, Gladman DD. Psoriatic arthritis: Phenotypic variance and nosology. Curr Rheumatol Rep. 2013;15(3):316.

20. Soriano ER, Marin J, Acosta-Felquer ML. Psoriatic arthritis: new evidence for old concepts. Curr Opin Rheumatol. 2018;30(1):87-93.

21. Gladman DD, Mease PJ, Strand V, Healy P, Helliwell PS, Fitzgerald $\mathrm{O}$, et al. Consensus on a core set of domains for psoriatic arthritis. J Rheumatol. 2007;34(5):1167-70.

22. Coates LC, FitzGerald O, Gladman DD, McHugh N, Mease P, Strand V, et al. Reduced joint counts misclassify patients with oligoarticular psoriatic arthritis and miss significant numbers of patients with active disease. Arthritis Rheum. 2013;65(6):1504-9.

23. Helliwell PS, Porter G, Taylor WJ, CASPAR study group. Polyarticular psoriatic arthritis is more like oligoarticular psoriatic arthritis, than rheumatoid arthritis. Ann Rheum Dis. 2007;66(1):113-7.

24. Delle SA, Riente L. Psoriatic arthritis: what ultrasound can provide us. Clin Exp Rheumatol. 2015;33(5 Suppl 93):S60-5.

25. van Mens LJJ, van de Sande MGH, Fluri IA, Atiqi S, van Kuijk AWR, Baeten DLP. Residual disease activity and treatment adjustments in psoriatic arthritis in current clinical practice. Arthritis Res Ther. 2017;19(1):226.

26. Huscher D, Albrecht K, Bischoff S, et al. Patients with psoriatic arthritis and oligoarthritic subtype report higher disease burden than patients with a polyarthritic pattern-data from the German Collaborative Arthritis Centres. Arthritis Rheumatol. 2015;67(suppl 10) (Abstract number: 679). 
27. Mease PJ, Coates LC. Considerations for the definition of remission criteria in psoriatic arthritis. Semin Arthritis Rheum. 2018;47(6):786-96.

28. Kavanaugh A, Fransen J. Defining remission in psoriatic arthritis. Clin Exp Rheumatol. 2006;24(6 Suppl 43):S83-7.

29. Coates LC, Fransen J, Helliwell PS. Defining minimal disease activity in psoriatic arthritis: a proposed objective target for treatment. Ann Rheum Dis. 2010;69(1):48-53.

30. Coates LC, Moverley AR, McParland L, Brown S, Navarro-Coy N, O'Dwyer JL, et al. Effect of tight control of inflammation in early psoriatic arthritis (TICOPA): a UK multicentre, open-label, randomised controlled trial. Lancet. 2015;386(10012):2489-98.

31. Coates LC, Helliwell PS. Methotrexate efficacy in the tight control in psoriatic arthritis study. J Rheumatol. 2016;43(2):356-61.

32. Coates LC, Mahmood F, Emery P, Conaghan PG, Helliwell PS. The dynamics of response as measured by multiple composite outcome tools in the TIght COntrol of inflammation in early Psoriatic Arthritis (TICOPA) trial. Ann Rheum Dis. 2017;76(10):1688-92.

33. O'Dwyer JL, Meads DM, Hulme CT, Mcparland L, Brown S, Coates LC, et al. Cost-effectiveness of TIght COntrol of inflammation in early Psoriatic Arthritis: economic analysis of a multicenter randomized controlled trial. Arthritis Care Res (Hoboken). 2018;70(3):462-8.

34. Kingsley GH, Kowalczyk A, Taylor H, Ibrahim F, Packham JC, McHugh NJ, et al. A randomized placebo-controlled trial of methotrexate in psoriatic arthritis. Rheumatology (Oxford). 2012;51(8):1368-77.

35. Iannone F, Lopriore S, Bucci R, Scioscia C, Anelli MG, Notarnicola A, et al. Two-year survival rates of anti-TNF-alpha therapy in psoriatic arthritis (PsA) patients with either polyarticular or oligoarticular PsA. Scand J Rheumatol. 2015;44(3):192-9.

36. Mease P. Methotrexate in psoriatic arthritis. Bull Hosp Jt Dis. 2013;2013(71 Suppl 1):S41-5. 